
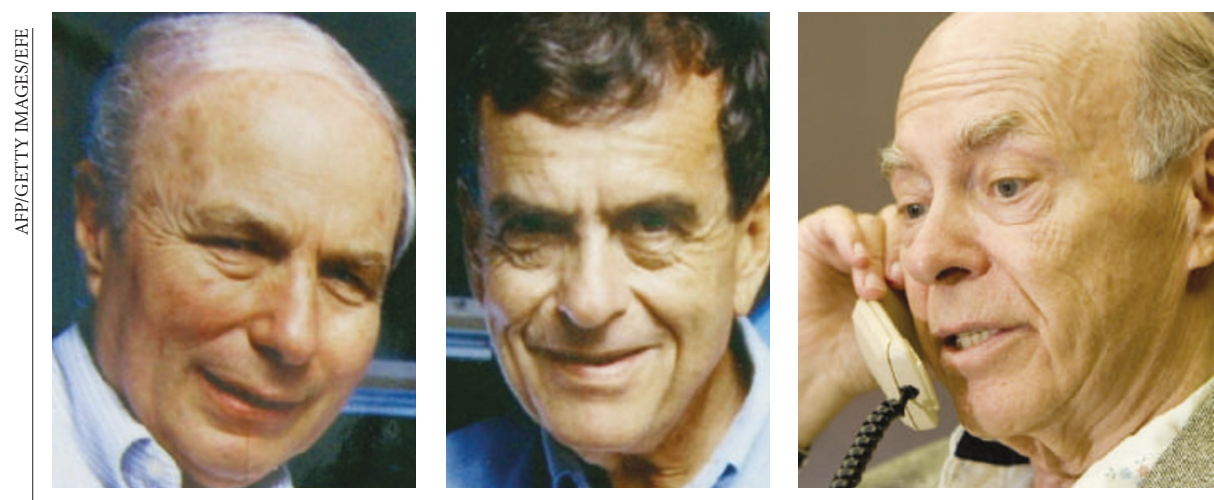

All for one, from left: Hershko, Ciechanover and Rose worked together on the ubiquitin kiss of death.

\title{
Chemistry Nobel for trio who revealed molecular death-tag
}

Jim Giles

Avram Hershko thought he might have a chance of winning this year's Nobel prize for medicine. So when the results were announced last week, and his name wasn't on the list, Hershko decided to spend some time by the pool with his granddaughters: "Maybe some other year, I thought."

But for Hershko, a biochemist at the Israel Institute of Technology in Haifa, it turned out to be the right year after all. While he was enjoying his holiday, Israeli radio announced on 6 October that he was a co-winner of this year's chemistry Nobel prize, together with Aaron Ciechanover, also at Haifa, and Irwin Rose of the University of California, Irvine. Hershko found out when his cousin phoned and told him.

The trio was rewarded for unravelling the mechanism behind a molecular kiss of death - a tag that marks proteins for destruction. The finding sparked new ideas about how cells regulate themselves, and spurred new directions in cancer research. "Their work is seminal," says Paolo di Fiore, a biochemist at the FIRC Institute of Molecular Oncology in Milan, Italy. "It affects every aspect of cell biology."

The laureates revealed the molecule that serves as this tag in two pioneering papers (A. Ciechanover et al. Proc. Natl Acad. Sci. USA 77, 1365-1368; 1980 and A. Hershko et al. Proc. Natl Acad. Sci. USA 77, 1783-1786; 1980). They later realized that the molecule was ubiquitin - a small protein that had been identified in 1975 by other researchers, but whose function had not previously been known.

Ubiquitin molecules can be found in many parts of the body - hence its name, taken from the Latin for 'everywhere'. Following the prizewinning discovery, biochemists now know that proteins are tagged with several ubiquitin molecules before being shuttled to the proteasome, a barrelshaped structure that chops up proteins.
"Once the pattern was clear, work blossomed into a huge number of areas," says Jeremy Berg, director of the National Institute of General Medical Sciences in Bethesda, Maryland.

Cancer researchers, for example, subsequently learned that ubiquitin regulates the levels of the protein p53, dubbed the 'guardian of the genome' for its role in protecting against cancer.

In a normal cell, ubiquitin regularly binds to p53 proteins, shunting them off for destruction in the proteasome. In cells where the DNA has been damaged, ubiquitin does not bind to $\mathrm{p} 53$, allowing levels of the protein to build up. This, in turn, stops cell division, allowing DNA repair systems get to work, or leading to the death of the cell if the damage is too great. In many tumours, this safetycontrol system has been disabled, allowing mutant cells to survive and multiply. This realization has led to the development of anticancer drugs that mimic this system to halt cell division.

Another contributor to this work on protein degradation was Alexander Varshavsky, a cell biologist at the California Institute of Technology in Pasadena. In 2000, Varshavsky shared the prestigious Albert Lasker Award for Basic Medical Research with Ciechanover and Hershko for work on ubiquitin. But he is absent from the list of Nobel winners.

Berg suggests that this may be because Varshavsky's work, which confirmed theories about ubiquitin by studying its action in yeast, may have been judged to be closer to cell biology than biochemistry - making it a step too far removed for a chemistry prize. Rose, in contrast, laid the groundwork for the 1980 papers by studying the chemistry that underlies the ubiquitin pathway.

"I'm very, very sorry for Varshavsky," says Hershko. "He really deserves it. The importance of what we had done only became clear after Varshavsky's work. I'd be happier if there could be four winners."

\section{'Memory of water' biologist dies after heart surgery}

Philip Ball, London

Jacques Benveniste, the French immunologist who claimed that water has a 'memory' - a putative explanation for homeopathic medicine - died on 3 October in Paris after heart surgery. He was 69 years old.

Benveniste was a maverick whose theories on molecular signalling in cell biology were dismissed by many other researchers. Yet his charm, charisma and rhetorical flair earned him a large following in France, and he remained genuinely convinced that he had discovered something important.

Much of his celebrity sprang from a Nature paper in 1988 - published with an unusual rider from John Maddox, the journal's editor at that time, pointing out that, at face value, the findings were unbelievable (see Nature 333, 816-818; 1988). According to Benveniste's paper, water that had once contained biomolecules, but had been diluted until it was devoid of any active agents, could still have a biological effect. The paper described white blood cells involved in allergic responses being activated by such a solution of antibodies.

At the time, Benveniste was research director of the Clamart-based Unit 200 of INSERM, the French biomedical research agency, which studied the immunology of allergy and inflammation. He was temporarily suspended after Maddox launched an investigation of his methods with the help of fraud investigator Walter Stewart and stage magician James Randi. Benveniste complained that this amounted to a "Salem witch hunt".

Although Benveniste's results were widely disbelieved by scientists and were not reproduced elsewhere, they were hailed in the popular press as a validation of homeopathy. The 'memory of water' was never clearly explained; Benveniste suggested that quantum-mechanical effects might be involved.

Benveniste continued to investigate biomolecular behaviour at high dilution, and concluded that molecular signalling occurs by electromagnetic transmission. He published claims that he had induced cell responses by playing back digitally recorded molecular signals in the absence of the molecules.

Although he kept up an association with INSERM, his studies during the past decade were conducted primarily at his privately funded Digital Biology Laboratory in Clamart. 